\title{
A ideologia gerencialista no Sistema Único de Saúde (SUS): a organização do trabalho de médicos
}

The managerialist ideology in the Unified Health System (SUS): the organization of work of doctors

La ideología gerencialista en el Sistema Único de Salud (SUS): la organización del trabajo de los médicos

\section{Luiz Gonzaga Chiavegato Filho* \\ Vera Lucia Navarro*}

\section{Resumo}

As recentes mudanças no universo do trabalho alteraram o processo, a organização

e as relações trabalhistas de diferentes categorias profissionais, inclusive a médica, repercutindo nas condições de trabalho e na saúde dos trabalhadores. Com base nesse cenário, esta pesquisa objetivou investigar a presença da ideologia gerencialista nas relações de trabalho de médicos do Sistema Único de Saúde do Município de Jaguariúna (SP). Foram entrevistados 15 médicos e 2 gestores da Secretaria de Saúde do Município. Os dados obtidos revelaram que aqueles profissionais estão submetidos a um processo de trabalho com forte influência da ideologia gerencialista, que lhes tira a autonomia para gerir o próprio trabalho, sobrecarregam-nos e os expõem a situações de muita pressão, interferindo em suas condiçóes de vida e saúde.

Palavras-chave: Sistema Único de Saúde. Médicos. Saúde do trabalhador. Psicologia do trabalho. Ideologia gerencialista.

\begin{abstract}
Recent changes in the world of work have modified the process, the organization and the labor relations among different professional categories, including the medical category. All these changes have affected the work conditions and also workers health. Based on this scenario, this study is aimed at investigating the presence of managerialist ideology in labor relations in the Sistema Único de Saúde (Unified Health System)
\end{abstract}

Membro do Departamento de Psicologia Universidade Federal de São João del-Rei (MG) (UFSJ). E-mail: lgcfilho@ufsj. edu.br.

* Membro do Departamento de Psicologia Faculdade de Filosofia, Ciências e Letras de Ribeirão Preto (USP). E-mail: vnavarro@usp.br. 
at Jaguariúna (SP). The study was conducted through the interviewing of fifteen doctors and two managers of the Sistema Único de Saúde (county Health Department). The obtained data revealed that those professionals are undergoing a process of work with strong influence of the managerialist ideology that takes away the autonomy to manage their own work. They are also overloaded and exposed to a lot of pressure situations which end up interfering their living conditions and health.

Keyword: Public health system. Unified Health System. Doctors. Labor health. Work Psychology. Managerialist ideology.

\section{Resumen}

Los recientes cambios en el mundo del trabajo, alteraron el proceso, la organización y las relaciones laborales de las distintas categorías profesionales, incluyendo la médica, afectando las condiciones de trabajo y salud de los trabajadores. En base a este escenario, este estudio tuvo como objetivo investigar la ideología gerencialista en las relaciones laborales en el Sistema Único de Salud (Seguridad Social) en el municipio de Jaguariúna (SP). Para llevar a cabo el estudio se entrevistó a 15 médicos y 2 gerentes de la Secretaría de Salud del Municipio. Los datos revelaron que los profesionales están sometidos a un proceso de trabajo con una fuerte influencia de la ideología gerencialista que les quita la autonomía para administrar su propio trabajo, los sobrecarga y los expone a situaciones de mucha presión, interfiriendo en sus condiciones de vida y salud.

Palabras clave: Sistema Nacional de Salud (Seguridad Social). Médicos. Salud del trabajador. Psicología del trabajo. Ideología gerencialista.

\section{Introdução}

Was últimas décadas, as transformações ocorridas no mundo do trabalho favoreceram o avanço da ideologia gerencialista para quase todas as esferas sociais, econômicas e políticas que regem as nossas vidas e o nosso cotidiano, promovendo a descrição, explicação e interpretação do mundo com base nas categorias da gestão corporativa, ocultando a realidade do poder subjacente (Gaulejac, 2007).

Em estudo conduzido por Chanlat (2002, p. 2), observou-se que noções e princípios administrativos da gestão privada, como competência, qualidade total, cliente, excelência, produto, etc., têm, efetivamente, "invadido amplamente as escolas, as universidades, os hospitais, as administrações, os 
serviços sociais, os museus, os teatros, as entidades sem fins lucrativos, e até as igrejas". Da mesma forma, palavras como empreendedorismo, gestão e manager, entre outras, são usadas de forma natural no dia a dia das pessoas.

Nas relações de trabalho, nota-se que o avanço da ideologia gerencialista promove uma forte "psicologização" dos problemas organizacionais, nas quais os trabalhadores são praticamente forçados a se colocarem como inconvenientes e debilitados, além de responsáveis pela situação em que se encontram, o que contribui para a crescente culpabilização individual e para a fragilização dos coletivos de trabalho. Tal condição promove o crescimento das queixas que se referem ao sofrimento psíquico, à hiperatividade, ao esgotamento profissional e ao aumento de suicídios no local de trabalho (Enriquez, 1995; Gaulejac, 2007).

Em pesquisas sobre trabalhadores da saúde no setor público, alguns estudos apontam que a presença da ideologia gerencialista está atrelada à sua precarização, uma vez que se observam a ausência de concursos públicos, o aviltamento de carreiras e salários, as terceirizações aleatórias, o aumento dos contratos temporários, as avaliações de desempenho descontextualizadas, que, entre outros fatores, comprometem a relação dos trabalhadores com a organização das unidades de atenção e prejudicam a qualidade e a continuidade dos serviços essenciais prestados pelo SUS. Configura-se, assim, um importante obstáculo para o desenvolvimento dos serviços da rede pública de saúde no Brasil (Elias, 2004; Assunção, Belisário, Campos \& D’Ávila, 2007; Santos, 2008; Assunção \& Brito, 2011; Chiavegato \& Navarro, 2012).

Tal precarização do processo de trabalho em saúde agrega novas pressões pessoais e sociais aos respectivos profissionais, inclusive os médicos. Observa-se a inadequação das condições materiais e organizacionais nos estabelecimentos de saúde, que provocam fadiga, crescente insatisfação no trabalho, ausência de reconhecimento e problemas de saúde mental, condiçóes estas traduzidas em transtornos psíquicos comuns, fragilização das instâncias coletivas nos ambientes de trabalho e empobrecimento da identidade profissional e do sentido do trabalho (Nogueira-Martins, 2003; Melo, Assunção \& Ferreira, 2007; Barbosa, Andrade, Carneiro \& Gouveia, 2007; Franco, Druck \& Seligmann-Silva, 2010; Assunção, Tavares \& Serra, 2012).

No caso dos profissionais médicos, alguns estudos, como os de Maciel \& Pierantoni (2004); Santos et al. (2006); Nascimento, Carvalho, Bonfim, Cirino e Ferreira (2006); Schraiber (2008) e Maciel et al. (2010), demonstram que tais mudanças, ainda em curso, repercutem na sua autonomia profissional; na remuneração (assalariamento crescente); nos múltiplos vínculos 
empregatícios; na rotinização e precarização do trabalho; no empobrecimento da relação médico-paciente; em seu comportamento ético; e, finalmente, na saúde desses profissionais.

Particularmente em relação à saúde dos médicos, entre outros motivos, os principais problemas encontrados foram os transtornos mentais, sobretudo os transtornos psíquicos menores, o uso abusivo de drogas e o suicídio (Cohen \& Rhydderch, 2006; Nascimento et al., 2006; Barbosa, Andrade, Carneiro, \& Gouveia, 2007; Miller, 2009).

Diante desse cenário, percebeu-se a necessidade de desenvolver um estudo que tivesse como objetivo investigar a presença da ideologia gerencialista nas relações de trabalho de médicos do SUS do Município de Jaguariúna-SP.

\section{Métodos}

Trata-se de pesquisa qualitativa, feita por meio de um estudo de caso (Yin, 2005), com médicos de unidades básicas de saúde (UBS) do SUS do Município de Jaguariúna-SP. Foram entrevistados 15 médicos (10 homens e 5 mulheres) das UBS de Jaguariúna, de diferentes especialidades: 8 clínicos gerais, 1 geriatra, 3 pediatras e 3 ginecologistas. Além deles, participaram dois gestores da Secretaria de Saúde do Município, 1 médico e 1 técnica de enfermagem, o secretário municipal e a diretora administrativa, respectivamente.

Todas as entrevistas foram individuais, abertas e realizadas nas dependências da UBS do Município, no período de setembro de 2007 a março de 2008. Foram guiadas por um roteiro que apresentava a seguinte questão inicial: "Fale-me sobre como percebe a profissão médica nos dias de hoje". Em seguida, abordava questôes sobre as condições e a organização do trabalho e os respectivos efeitos na saúde física e mental; o médico como trabalhador assalariado; a qualidade das relações com pacientes, colegas, hierarquia e com sua própria atividade no interior das UBS. A duração dos depoimentos variou de 30 a 60 minutos, dependendo da disponibilidade dos médicos.

$\mathrm{Na}$ época da pesquisa, os médicos das UBS cumpriam uma jornada de, no mínimo, 20 horas semanais, controladas pelo cartão de ponto. Alguns deles distribuíam a sua carga horária por mais de uma UBS. Havia 33 médicos efetivamente contratados no período da pesquisa, trabalhando não só nas UBS, mas em outros setores da Secretaria de Saúde.

Os critérios para a inclusão dos entrevistados foram definidos visando a garantir a presença de, pelo menos, um médico de cada UBS e de cada especialidade médica oferecida em tais serviços. Além desses, foram 
observados os seguintes critérios: ser do quadro efetivo e estável da Prefeitura Municipal de Jaguariúna, ter mais de um ano de atuação nesse emprego, estar no desempenho de atividades profissionais no período da coleta de dados e aceitar que as entrevistas fossem gravadas e, posteriormente, transcritas na íntegra.

Na apresentação dos dados, optou-se por se referir aos médicos entrevistados por letras do alfabeto, visando a garantir o sigilo dos depoimentos. A análise dos dados foi construída por meio de um processo contínuo em busca da identificação de dimensões, categorias, tendências, padrões, relações, desvendando-lhes o significado. Afinal, trata-se de um processo complexo, não linear, que implica um trabalho de redução, organização e interpretações dos dados que acompanhou todo o processo de investigação.

Esta pesquisa seguiu as normas da Resolução 196/1996 (Ministério da Saúde, 2006b) do Conselho Nacional de Saúde e foi aprovado pelo Comitê de Ética em Pesquisa da Faculdade de Filosofia, Ciências e Letras de Ribeirão Preto (Processo CEP-FFCLRP no 387/2008). Tanto na primeira quanto na segunda etapa, os médicos foram esclarecidos sobre os procedimentos da pesquisa e, em seguida, assinaram o termo de consentimento livre e esclarecido.

\section{A ideologia gerencialista no trabalho dos médicos}

Em 2008, a rede pública municipal de saúde de Jaguariúna contava com os seguintes serviços: um ambulatório odontológico e outro de saúde mental; Departamento de Vigilância em Saúde, para serviços epidemiológicos e sanitários; Centro de Reabilitação Fisioterápica, em convênio com a Faculdade de Jaguariúna; Central de Ambulâncias; Central de Medicamentos; e as cinco UBS.

Em termos administrativos e técnicos, no organograma da Secretaria da Saúde, as UBS estavam vinculadas à Diretoria de Saúde, cuja tarefa principal, na prática, restringia-se apenas a resolver questôes administrativas e burocráticas, fato que evidenciou a ausência de prescrição do trabalho médico. Uma boa prescrição dos serviços e práticas a serem desenvolvidos pelos profissionais, não só médicos e não só da área da saúde, é uma importante função de qualquer gestor, de modo que possa servir como uma orientação inicial e que possa ser constantemente renovada pelo coletivo de trabalhadores. $\mathrm{O}$ não cumprimento dessa função pode desencadear uma série de problemas, como insatisfação profissional e até um empobrecimento da identidade profissional. Tal condição foi apontada em alguns depoimentos: 
Feedback é importante, e até hoje não foi feita nenhuma reunião com os médicos. Quando cheguei, eu fui jogado lá no posto de saúde, não recebi nenhum treinamento. (Médico B)

Quando entrei, eu era recém-formado, fui lá $[\mathrm{UBS}]^{1}$ e tive que atender 32 pacientes por dia, com o que tinha lá. Ninguém me falou como deveria ser, nem pra preencher os formulários. (Médico I)

Queixas desse tipo foram evidenciadas nesses e em outros depoimentos, sobretudo junto aos médicos novatos do serviço, confirmando a ausência de atuação, por parte dos gestores das UBS, sobre a dimensão técnica do trabalho médico, deixando aos próprios profissionais individualmente a decisão sobre como deveriam proceder em suas práticas e rotinas cotidianas.

Todavia essa circunstância não é propriamente um privilégio desse Município. Outros estudos também mostraram que, normalmente, a gestão tanto do trabalho médico como dos demais profissionais de saúde restringe-se a questões administrativas de cumprimento de horário, tempo de consulta, metas de produção, etc. Além disso, particularmente no caso do trabalho médico, apontam que tal condição ocorre, frequentemente, por resistência do próprio profissional em aceitar mudanças tanto na sua prática como no modelo assistencial adotado pelo respectivo Município (Mendes-Gonçalves, 1994; Capozzolo, 1997, 2003).

Em termos administrativos, em cada UBS do Município de Jaguariúna, havia uma coordenação, exercida sempre por uma enfermeira, que se responsabilizava pela organização do trabalho na unidade, ou seja, a organização da marcação das consultas, a distribuição dos profissionais pelas salas e a rotina em geral. Tratava-se de um cargo exercido informalmente, pois não existia de fato e nem havia remuneração extra para ele: entendia-se que era parte do trabalho atribuído às enfermeiras. No entanto, isso, eventualmente, gerava conflitos na administração dos serviços oferecidos dentro de cada unidade. Muitas vezes, as enfermeiras tinham suas decisões questionadas pelos demais funcionários, principalmente pelos médicos, que não reconheciam sua autoridade, e os problemas acabavam sendo resolvidos em instâncias superiores.

A questão da hierarquia é um problema bastante recorrente na gestão do trabalho médico. Tal categoria profissional, na maioria das vezes, costuma delegar apenas aos seus pares a possibilidade de avaliação, desenvolvimento e controle sobre seu trabalho, mesmo assim, de forma relutante, sobretudo se a gerência for exercida por profissionais não médicos (Capozzolo, 1997).

Todos os colchetes encontrados nos trechos dos depoimentos apresentados são nossos. 
Além de se limitar a questôes administrativas da organização do trabalho médico, em detrimento de orientaçōes técnicas, foi possível observar, no depoimento dos gestores, a presença da ideologia gerencialista. Tanto a partir do vocabulário característico como também, entre outros aspectos, da ênfase no indivíduo como principal ou até mesmo o único responsável pelas ações no trabalho, da presença de uma racionalidade instrumental na organização dos atendimentos médicos prestados nas UBS e na idealização da gestão corporativa privada, como solução para os males da gestão pública.

Um colaborador não tem que estar atrelado ao que está determinado que ele faça e sim deve fazer além do que está determinado que ele faça. Isso é o ideal. (Gestor B)

Hoje, vendo o que a gente tem de mudança, é ter uma flexibilidade maior. É eles trabalharem o que eles podem e assumir o que eles podem cumprir. Precisa partir da vontade deles. (Gestor A)

Como afirmado no início desse artigo, é possível, atualmente, identificar a forte presença do vocabulário gerencialista não só no cotidiano de diversos ambientes de trabalho como também no dia a dia das pessoas e em diferentes tipos de instituições, inclusive as do setor público. Palavras como empreendedorismo, gestão, vontade, manager, flexibilidade, entre outras, costumam ser usadas de forma naturalizada, ignorando sua determinação social e contribuindo para o entendimento de que os indivíduos são os únicos responsáveis pelo seu desempenho (Chanlat, 2002; Gaulejac, 2007; Wood \& Paula, 2010).

Por conta do predomínio desse modo de gestão, outras formas de administração que se opõem a esse ideário são vistas como obsoletas e desatualizadas. Em vários momentos dos depoimentos dos gestores, essa questão aparece de forma clara:

Nas empresas novas, eles estimulam as pessoas, é diferente. Eles procuram ter uma dinâmica melhor. Se você produz bem, seu produto fica bom; se vende bem, tudo é bom! No serviço público, não! A gente ainda tem muito ranço, assim, as pessoas não sabem se desprenderem de questōes pessoais, políticas, entendeu! (Gestor A)

$\mathrm{O}$ dia que isso aqui for gerenciado como uma empresa, para fazer bem feito, entendeu [...] $\mathrm{O}$ dia que a gente aprender a fazer isso, todo mundo, você tem que participar! Você tem que fazer mudar! Tem que ser profissional! Acima de qualquer coisa, acima de vontade política, amiga, etc.! (Gestor A) 
A presença do ideário gerencialista prossegue em outros momentos dos depoimentos dos gestores, quando enfatizam a importância do novo perfil profissional no mundo do trabalho e a consequente mobilização da subjetividade sobre objetivos, resultados, critérios de sucesso, que tendem a eliminar o que não é útil ou rentável:

O meu conceito é que ele deveria ter uma responsabilidade, um comprometimento maior, mas ele [o médico] não tem. (Gestor A)

Ele [o médico] deveria ser tratado [de maneira diferenciada] se tivesse um comprometimento diferente. (Gestor B)

Esse novo perfil profissional caracteriza-se, entre outras coisas, pela demonstração de comprometimento, disponibilidade e responsabilidade do trabalhador nos ambientes de trabalho, além de outras características mais conhecidas, como flexibilidade, criatividade, adaptação às mudanças, inovação e trabalho em equipe (Merlo \& Lapis, 2007; Wood \& Paula, 2010).

Atualmente, os gestores têm se concentrado basicamente na construção desse perfil no interior dos ambientes de trabalho, o que finda por prescrever a subjetividade dos trabalhadores, visando a garantir comprometimento e disponibilidade dos trabalhadores para as instituições. Trata-se, de acordo com Gaulejac (2007), da prescrição de condutas tidas como corretas nos locais de trabalho, que devem ser desenvolvidas pelos próprios trabalhadores, independentemente da relação com o trabalho. Esse tipo de visão acaba culpando o trabalhador e inocentando a gestão, as condições e a organização do trabalho. Um exemplo disso pode ser notado no seguinte trecho do depoimento de um dos gestores:

As pessoas têm que entender que as coisas [problemas de relacionamento interpessoal] passam. Por isso é que tem serviço que não desentrava [...], as pessoas têm que perder isso, funcionar melhor, vamos ter uma meta! Vamos tentar cumprir! Mas isso é mais no serviço público mesmo. (Gestor $\mathrm{A}$ )

A gente não aprendeu a ter esse tipo de gerência aqui [referindose ao setor privado], infelizmente! É uma questão de aprendizado das pessoas, isso tudo também. (Gestor A)

A concentração, por parte dos gestores, não nas condições reais de trabalho, mas, sobretudo, na prescrição da subjetividade, ou seja, na padronização de comportamentos e competências pessoais necessárias para determinadas tarefas, faz com que sujeitos se transformem em "objetos" de trabalho, visando a garantir comprometimento e disponibilidade dos trabalhadores 
para a empresa ou serviço. Essa condição tem implicações não só na qualidade do trabalho, mas também, no caso dos médicos entrevistados, nas condições de saúde desses profissionais. Embora não seja esse o foco deste artigo, vale trazer alguns depoimentos referentes a um dos problemas de saúde que se destacaram: a hipertensão.

Sempre tem [impacto na saúde]. Outro dia, a pressão subiu. Descompensou. (Médico B)

$\mathrm{Eu}$ acho que, depois que eu comecei a fazer esse posto [UBS], começou a mexer na minha pressão de novo. (Médica C)

Eu estou fazendo [tratamento médico], estou controlando a minha pressão. (Médico K)

Para Enriquez (1995), a prescrição da subjetividade faz parte de um movimento que representa o apogeu $\mathrm{da}$ racionalidade instrumental, consolidada pelo modelo taylorista/fordista de produção, porém de forma mais sutil e mais insidiosa. Como citado acima, essa condição tem promovido uma psicologização dos problemas, em que os indivíduos alienados não questionam mais o papel da organização do trabalho nos respectivos desempenhos. Dessa maneira, já não se questionam mais os modos de organização e de gestão, somente as características pessoais dos trabalhadores são levadas em consideração.

Em outro trecho do depoimento de um dos gestores, a questão da racionalidade instrumental aparece na intenção de padronizar os atendimentos oferecidos nas UBS. Trata-se da construção de protocolos clínicos de conduta para cada tipo de tratamento oferecido pelo profissional médico.

\footnotetext{
Tanto o Conselho Federal de Medicina quanto a Associação Médica Brasileira criaram um projeto de diretrizes que são protocolos clínicos para se tentar uniformizar a conduta do médico [...] é esse caminho que tem que ser seguido, porque o indivíduo tem que ser tratado aqui em Jaguariúna de um jeito e em Taubaté do mesmo jeito. (Gestor B)
}

Alguns autores identificaram que as principais influências para o setor da saúde, decorrentes das transformações no mundo do trabalho e da ascensão da ideologia gerencialista, sobretudo a partir da década de 1980, concentramse na questão do planejamento estratégico e do gerenciamento flexível e participativo. Somados a esses elementos estão também os processos de controle de qualidade em saúde, que definem a melhor conduta por meio da padronização dos atendimentos por meio de protocolos, como sugerido pelo gestor entrevistado, e a manutenção do foco no cidadão/usuário, reconhecendo suas necessidades e expectativas, visando a facilitar o acesso aos 
serviços públicos (Deluiz, 2001; Peduzzi, 2002; Guimarães, 2009; Campos, 2010).

Essa tendência aparece na fala dos gestores sobre a organização do trabalho dos médicos, quando se referem à dificuldade de controlar o processo de trabalho, de estabelecer o trabalho em equipe, normas de conduta, entre outros:

Essa relação nunca é excelente [com os médicos]. Você pode ter relação boa de amizade, mas, na hora em que você pega para gerir, acaba tendo que ser chato. Você tem que impor horários, tem que impor limites, impor protocolos... (Gestor B)

É muito complicado de eles [os médicos] aceitarem normas, aceitarem as definições, de cumprirem regras, horários, etc. (Gestor A)

Nota-se também a presença dos princípios tayloristas/fordistas na fala dos gestores, como de resto nas práticas de gestão de serviços de saúde no Brasil, reforçada pela forte especialização e fragmentação disciplinar no campo da saúde. Esse cenário apresenta, de acordo com Campos (2010), ao menos três características principais, todas evidentemente interligadas e dependentes uma das outras: tendência a subordinar o trabalho a modos de funcionamento padronizados a priori; criação de instrumentos disciplinares para exercer o controle sobre o trabalho e os trabalhadores em particular; e, por fim, adoção de uma visão reducionista e mecânica acerca da natureza humana.

No entanto, as tentativas de gerenciamento do trabalho em saúde, com base nos princípios tayloristas/fordistas e no ideário gerencialista, configuram-se como uma missão difícil de ser executada na prática, pela própria natureza do objeto desse trabalho, o ser humano e sua variabilidade inerente. De modo que um determinado grau de autonomia para o profissional é imprescindível. Como afirma Merhy (2002), o processo de trabalho em saúde é resistente às tentativas de enquadramento e controle por parte das "lógicas gerenciais", uma vez que os profissionais da saúde devem ter um espaço próprio de gestão de seu trabalho, por conta da relação privada que estabelecem com os usuários dos serviços.

Considerando-se, conforme a visão marxista, que os seres humanos são ativos, reflexivos e modificam o seu funcionamento concreto de acordo com determinado contexto histórico, cultural, econômico e social, produzindo espaços singulares de existência, questiona-se como é possível pensar numa proposta gerencial que contemple todos esses aspectos, ou ainda, que permita 
que o trabalhador desenvolva sua capacidade de reflexão e intervenção sobre as situações de trabalho.

Assim, a proposta contida no ideário gerencialista também não avança muito nesse aspecto, uma vez que procura restringir o processo de trabalho em saúde, por meio da padronização dos procedimentos. De qualquer forma, as interferências dessas novas tendências de gestão, provocadas no trabalho em saúde, ainda precisam de uma melhor compreensão (Campos, 2010).

No entanto, pelo que foi até agora apresentado, é possível afirmar que a gestão da saúde em Jaguariúna-SP está fundamentada nos princípios e pressupostos da "administração pública gerencial". Tais princípios e pressupostos estão, de acordo com Wood e Paula (2010), ligados à ideologia gerencialista por enaltecer as noções de empreendedorismo, o culto à performance e à excelência, a motivação, a inovação e a responsabilidade social, em busca do controle, da eficiência e da competitividade.

De acordo com Paula $(2005,2010)$, além desse modelo que se articula com as estratégias neoliberais de estabilização econômica e estratégias administrativas orientadas para o mercado, há o modelo da "administração pública societal". Tal modelo está ligado a movimentos de reforma política e ideológica que tiveram o seu apogeu na década de 1960, como o Movimento Sanitário, no caso da saúde especificamente. Esses movimentos buscavam, entre outras coisas, substituir a "gestão tecnoburocrática", proporcionando maior participação dos cidadãos e dos trabalhadores no processo decisório. Porém esse não é o caso do modelo de organização do trabalho em saúde constatado em Jaguariúna.

A terceirização de parte dos serviços prestados pela Prefeitura Municipal, por meio de um convênio com a Associação Santa Maria de Saúde (Asamas), uma organização social (OS), para a administração do Hospital Municipal "Walter Ferrari", vale lembrar, é mais uma evidência do ideário gerencialista na gestão da saúde em Jaguariúna-SP. Entre os serviços terceirizados, estão a organização do serviço de pronta urgência, exames laboratoriais, cirurgias e consultas médicas em diversas especialidades. Os funcionários da Asamas não têm qualquer vínculo empregatício com a Prefeitura. Em alguns casos, no entanto, havia a possibilidade, caso houvesse necessidade, de um funcionário da Prefeitura prestar serviços na Asamas.

Entende-se que essa modalidade de gestão configura-se como uma forma de sucateamento do setor público e de precarização das relaçôes de trabalho, apesar de alardeadas como propostas administrativas que visam a preservar a qualidade, manter a eficiência, elevar o desempenho e os resultados (Maciel \& 
Pierantoni, 2004; Santos, 2008; Paula, 2010).

No entanto, concorda-se com Ribeiro (2009), que afirma que, apesar do predomínio do modelo de "administração pública gerencial" na maior parte dos municípios brasileiros, não é possível falar em "modelo puro" de gestão, e sim em modelos híbridos e mistos, pela própria dinâmica da organização do trabalho no setor público.

Outro aspecto importante que caracteriza a organização do trabalho médico em Jaguariúna, observado tanto nos depoimentos dos gestores quanto dos médicos, foi a ausência de um modelo assistencial definido para as práticas de atenção básica. Nesses casos, os serviços prestados nas UBS podem ser enquadrados no chamado "modelo de atenção primária convencional de saúde", caracterizado por uma atenção médica seletiva orientada pela demanda espontânea da população, que geralmente busca atendimento quando já tem algum problema de saúde:

Aqui, a gente trabalha muito na cura, a gente não faz uma prevenção antes. (Gestor A)

Se você vai ao pronto-socorro de Jaguariúna conseguir uma assistência, você é atendido em duas, três, quatro horas e sai de lá com os exames que precisam ser feitos já feitos e com o resultado e com a receita na mão [...] Mas se você vai ao posto de saúde [UBS], tem que agendar a consulta para 15 ou 20 dias, depois tem os exames que vão demorar mais uns 15 ou 20 dias, para daí conseguir a receita [...] Então, assim é difícil manter um modelo de prevenção como previsto pelo SUS. (Médico G)

Entendo que as UBS teriam que trabalhar na prevenção e na promoção da saúde. Mas isso eu nunca fiz. Só atendo à demanda, atendo a pessoa que já vem com um problema. (Médico B)

Esse modelo de atenção primária finda por ratificar um processo de produção de saúde baseado no paradigma médico tradicional, caracterizado pelo reducionismo, ao privilegiar os aspectos biológicos na determinação da relação saúde/doença, e pela promoção de uma assistência médica curativa e centrada na figura do profissional médico (Ronzani \& Stralen, 2003).

No entanto o fato de prevalecer o paradigma do modelo assistencial centrado na assistência médica individual e, portanto, na figura do médico, parece não ser uma prerrogativa só do Município de Jaguariúna-SP, uma vez que alguns estudos indicam que, em muitas localidades, persiste tal 
configuração da rede pública de saúde, mesmo com a reorientação do modelo assistencial fundamentada inicialmente no Programa de Agentes Comunitários de Saúde (PACS) e, em seguida, nas Estratégias da Saúde da Família (ESF) (Bertolozzi \& Greco, 1996; Costa, Cotta, Ferreira, Reis \& Franceschini, 2009).

Apesar dessas iniciativas de reorientação do modelo assistencial, há ainda inúmeras dificuldades e resistências a serem enfrentadas, como ampliar o conceito de saúde, visando a remodelar as práticas de saúde focadas na doença; privilegiar o interesse público, relegado a segundo plano diante dos interesses financeiros e comerciais; e, entre outros, superar a atenção médica fortemente especializada e fragmentada (Campos, 1997; Carvalho \& Ribeiro, 1998; Campos, 2010).

Parte dessas resistências deve-se ao fato de que, ao longo do século XX, o saber e a prática médica criaram uma forte estrutura de conhecimentos, amplo e exclusivo mercado de trabalho e forte credibilidade social. Para tanto, apoiaram-se na consolidação do processo capitalista de produção e no paradigma médico biologicista, de concepção mecanicista cartesiana. Nesse período, as políticas públicas de saúde que se opunham ao modelo assistencial curativo, derivado dessas condições, ficaram em segundo plano (Machado, 1997; Schraiber, 2000).

No final da década de 1990, para que as Estratégias da Saúde da Família viessem a ser, de fato, estratégias de reorganização da atenção à saúde no SUS, o Ministério da Saúde promoveu a implantação de polos de capacitação, formação e educação permanente para os profissionais envolvidos nessa proposta (Sousa \& Hamann, 2009).

No entanto, em Jaguariúna, essa ação resultou apenas em algumas oficinas para definição de aspectos pontuais das práticas oferecidas nas UBS, mas não para reorientação do modelo assistencial. Na maioria dos depoimentos dos médicos, foi possível observar algumas dificuldades em compreender tanto o SUS propriamente dito quanto a proposta de reorientação da atenção básica:

Quando eu fiz faculdade, a medicina social, o SUS, essa coisa toda [políticas de saúde], era uma coisa tão etérea, tão assim fora das coisas. Eu falava: gente, que coisa mais chata. Hoje entendo um pouco mais. (Médica A)

Quando você propõe uma tratativa de humanização [referindo-se às oficinas de humanização], você parte do pressuposto de que anterior a isso não havia [...] Então, eu 
vejo com certa dificuldade esse tema [...]. Eu acho que a situação é o não entendimento correto disso, da humanização. (Médico G)

Um trecho do depoimento de um dos gestores foi esclarecedor, apesar de, aparentemente, parecer contraditório, uma vez que credita aos médicos mais antigos o conhecimento acerca dos princípios do SUS, enquanto os mais novos não teriam tal conhecimento. Contraditório, porque, em tese, os mais novos deveriam, por meio da formação mais recente e, consequentemente, mais atualizada, conhecer melhor as propostas dessa política pública de saúde.

Eu acho que $30 \%$ dos médicos sabem, os outros $70 \%$, não [...] Os médicos antigos sabem, os novos não. Então eles se formam e começam a trabalhar sem ter essa visão do serviço público, um estudo prévio, uma experiência prévia no SUS. (Gestor A)

O que parece estar expresso nessa fala é justamente a mudança de modelo de prática profissional da medicina, de um modelo liberal, mais antigo, para um modelo tecnológico, mais recente, que se inicia na década de 1960 e se consolida nas décadas seguintes (Schraiber, 2000).

Os médicos mais experientes tendem a conservar aspectos da prática liberal, como a anamnese mais detalhada e a conversa prolongada, demonstrando mais atenção e disponibilidade para com o paciente. Por conta disso, acabam estabelecendo melhores relações com os usuários dos serviços de saúde (Schraiber, 1995, 2000).

A melhoria das relações entre os sujeitos envolvidos nas práticas de saúde do SUS é, justamente, uma estratégia do Ministério da Saúde (Ministério da Saúde, 2004, 2006a) visando à transformação dos modelos de atenção e de gestão nos serviços de saúde.

Já a maioria dos médicos mais novos tende a exercer uma medicina mais tecnicista, mais preocupada em promover arranjos econômicos do que sociais e afetivos, materializada na demanda crescente do número de atendimentos em um tempo cada vez menor e cada vez mais especializado, na institucionalização dos planos de saúde, do hospital como local prioritário de trabalho, etc. (Schraiber, 1995, 2000).

Com base no que foi apresentado acima, entende-se que a reorientação do modelo assistencial básico, nos moldes propostos pelas Estratégias da Saúde da Família e em conformidade com os princípios e diretrizes do 
SUS, e a construção de políticas públicas para possível aprimoramento da organização de trabalho em saúde configuram-se como um importante e difícil desafio, tendo em vista as dificuldades de superação de um modelo de prática de saúde, baseado na visão biologicista e mecanicista do processo saúde/doença e a hegemonia de formatos organizacionais baseados na ideologia gerencialista (Gaulejac, 2007; Santos, 2008; Cohn, 2009; Campos, 2010).

\section{Considerações finais}

Resultado da reestruturação produtiva no setor de saúde, o grande desenvolvimento tecnológico, voltado para a medicina e para a indústria farmacêutica, acrescido do crescimento das empresas compradoras de serviços médicos, compõe um novo cenário que altera o processo, a organização e as relações trabalhistas dos profissionais da medicina. Tais mudanças que resultaram, entre outras coisas, em maior intensificação e precarização do trabalho médico, repercutiram negativamente nas condições de trabalho e, consequentemente, na saúde daqueles profissionais.

Os dados obtidos na pesquisa revelaram que os médicos entrevistados estão submetidos a um processo de trabalho baseado no modelo de medicina tecnológica que lhes tira a autonomia para gerir o próprio trabalho, sobrecarrega-os e os expõe a situações de muita pressão. Além disso, observouse também um estranhamento dos médicos com relação ao seu trabalho, já que não se reconhecem na atividade a que se dedicam cotidianamente, alegando não terem apoio dos colegas para a execução das tarefas e nem reconhecimento por parte das chefias e dos pacientes.

Essa condição profissional se aprofunda, quando, além dos problemas de gestão do trabalho, os médicos vivenciam as dificuldades decorrentes do enfraquecimento de seu ofício, esgotamento da modalidade estritamente liberal de exercício da profissão, decorrente da crise da medicina provocada pela mudança de modelo orientador de suas práticas, como a passagem de um modelo liberal de exercício profissional para o modelo tecnológico e empresarial. Tal situação gera também implicações importantes numa questão central da profissão, que é a relação médico-paciente, promovendo um distanciamento entre as partes e desumanizando a prática profissional.

Diante desse cenário profissional, devem ser estimuladas ações de planejamento e gestão de serviços de saúde, que não se restrinjam a questões administrativas, mas que ampliem sua atuação em direção à prescrição técnica da prática médica, propondo ações de saúde vinculadas aos princípios básicos 
do SUS e que estimulem a interdisciplinaridade das técnicas e o trabalho em equipe. Tais açôes devem organizar e avaliar os atos médicos, com base em diretrizes que garantam a universalização e a equidade da atenção à saúde. Além disso, devem respeitar a autonomia técnica da profissão, além de questionar as práticas de controle hierárquico, político e institucional que parecem apenas reproduzir os interesses corporativos da profissão.

Recomenda-se a continuidade de estudos que busquem compreender as situações de trabalho e reconhecer a variabilidade humana presente nestas, com o intuito de conhecer os modos operatórios dos trabalhadores e as estratégias de regulação de suas atividades e práticas diante das exigências da organização de trabalho. O grande desafio é, com base nessa compreensão, criar estratégias de prevenção e de desenvolvimento da capacidade de ação dos trabalhadores sobre as situações de trabalho.

\section{Referência}

Assunção, A. A., \& Brito, J. (Org.). (2011). Trabalhar na saúde: experiências cotidianas e desafios para a gestão do trabalho e do emprego. Rio de Janeiro: Fiocruz.

Assunção, A. A., Belisário, S. A., Campos, F. E., \& D’Ávila, L. S. (2007). Recursos humanos e trabalho em saúde: os desafios de uma agenda de pesquisa. Cadernos de Saúde Pública, 23 (suppl. 2), 193-201.

Assunção, A. A., Tavares, I. R., \& Serra, P. J. (Org.). (2012). Panorama da saúde dos trabalhadores da saúde. Belo Horizonte: UFMG.

Barbosa, G. A., Andrade, E. O., Carneiro, M. B., \& Gouveia, V. V. (Org.). (2007). A saúde dos médicos no Brasil. Brasília: Conselho Federal de Medicina.

Bertolozzi, M. R., \& Greco, R. M. (1996). As políticas de saúde no Brasil: reconstrução histórica e perspectivas atuais. Revista da Escola de Enfermagem da USP, 30 (3), 380-398.

Campos, G. W. S. (1997). Reforma da Reforma: repensando a saúde. São Paulo: Hucitec.

Campos, G. W. S. (2010). Cogestão e neoartesanato: elementos conceituais para repensar o trabalho em saúde combinando responsabilidade e autonomia. Ciência \& Saúde Coletiva, 15 (5), 2337-2344. 
Capozzolo, A. A. (1997). Os desafios para o gerenciamento do trabalho médico: um estudo em unidades básicas do município de Diadema/SP. Dissertação de Mestrado, Universidade Estadual de Campinas, Campinas, SP, Brasil.

Capozzolo, A. A. (2003). No olho do furação: trabalho médico e o Programa de Saúde da Família. Tese de Doutorado, Universidade Estadual de Campinas, Campinas, SP, Brasil.

Carvalho, A. I., \& Ribeiro, J. M. (1998). Modelos de atenção à saúde. In A. I. Carvalho \& F. A. Goulart. Gestão em saúde. (pp. 473-487). Rio de Janeiro; Brasília: Fiocruz.

Chanlat, J. F. (2002). O gerencialismo e a ética do bem comum: a questão da motivação para o trabalho nos serviços públicos. Proceedings of the Congreso Internacional del CLAD sobre la Reforma del Estado y de la Administración Pública, 7, Lisboa. Recuperado em 13 janeiro, 2008, de http://www.imparh. ce.gov.br/eadgmf2012/GESTAO_PUBLICA_05_EADGMF.pdf

Chiavegato L. G. Filho, \& Navarro, V. L. (2012). A organização do trabalho em saúde em um contexto de precarização e avanço da ideologia gerencialista. Revista Pegada Eletrônica, 13 (2), 67-82.

Cohen, D., \& Rhydderch, M. (2006). Measuring a doctor's performance: personality, health and well-being. Occupational Medicine, 56 (7), 438-440.

Cohn, A. (2009). Saúde e desenvolvimento social. Saúde e Sociedade, 18 (suppl2), 41-47.

Costa, G. D., Cotta, R. M. M., Ferreira, M. L. S. M., Reis, J. R., \& Franceschini, S. C. C. (2009). Saúde da família: desafios no processo de reorientação do modelo assistencial. Revista Brasileira de Enfermagem, 62 (1), 113-118.

Deluiz, N. (2001). Qualificação, competências e certificação: visão do mundo do trabalho. Formação, 1 (2), pp. 5-15.

Elias, P. E. (2004). Estado e saúde: os desafios do Brasil contemporâneo. São Paulo em Perspectiva, 18 (3), 41-46.

Enriquez, E. (1995). Prefácio. In: Davel, E. P. B., \& Vasconcellos, J. G. M. (Org.). "Recursos" humanos e subjetividade. (pp. 7-22). Petrópolis: Vozes.

Franco, T., Druck, G., \& Seligmann-Silva, E. (2010). As novas relaçōes de trabalho, o desgaste mental do trabalhador e os transtornos mentais no trabalho precarizado. Revista Brasileira de Saúde Ocupacional, 35 (122), 229248.

Gaulejac, V. (2007). Gestão como doença social: ideologia, poder gerencialista e fragmentação social. São Paulo: Ideias e Letras. 
Gonçalvez, R. B. M. (1994). Tecnologia e organização social das práticas de saúde. São Paulo: Hucitec.

Guimarães, M. C. (2009). Transformações do trabalho e violência psicológica no serviço público brasileiro. Revista Brasileira de Saúde Ocupacional, 34 (120), 163-171.

Machado, M. H. (1997). Perfil dos médicos no Brasil. Rio de Janeiro: Fiocruz.

Maciel, R. Filho \& Pierantoni, C. R. (2004). O médico e o mercado de trabalho em saúde no Brasil: revendo conceitos e mudanças. In A. F. R. Barros (Org.). Observatório de Recursos Humanos em saúde no Brasil: estudos e análises. (pp.139-162). Brasília: Ministério da Saúde.

Maciel, R. H., Santos, J. B. F., Sales, T. B., Alves, M. A. A., Luna, A. P., \& Feitosa, L. B. (2010). Multiplicidade de vínculos de médicos no Estado do Ceará. Revista de Saúde Pública, 44 (5), 950-956.

Melo, E. M. C., Assunção, A. A., \& Ferreira, R. A. (2007). O trabalho dos pediatras em um serviço público de urgências: fatores intervenientes no atendimento. Cadernos de Saúde Pública, 23 (12), 3000-3010.

Mendes-Gonçalves, R. B. (1994) Tecnologia e organização social das práticas de saúde: características tecnológicas do processo de trabalho na rede estadual de Centros de Saúde de São Paulo. São Paulo: Hucitec/Abrasco.

Merhy, E. E. (2002). Saúde: a cartografia do trabalho vivo. São Paulo: Hucitec.

Merlo, A. R. C., \& Lapis, N. L. (2007). A saúde e os processos de trabalho no capitalismo: reflexôes na interface da psicodinâmica do trabalho e da sociologia do trabalho. Psicologia \& Sociedade, 19 (1), 61-68.

Miller, L. (2009). Doctors, their mental health and capacity for work. Occupational Medicine, 59 (1), 53-55.

Ministério da Saúde (2004). HumanizaSUS: Política Nacionalde Humanização: a humanização como eixo norteador das práticas de atenção e gestão em todas as instâncias do SUS. Brasília: Ministério da Saúde.

Ministério da Saúde (2006a). HumanizaSUS: documento base para gestores e trabalhadores do SUS. Brasília: Ministério da Saúde.

Ministério da Saúde. Conselho Nacional de Saúde. (1996b). Diretrizes e normas regulamentadoras sobre pesquisa envolvendo seres humanos. Resolução 196/1996. Brasília: CNS. 
Nascimento, C. L., Sobrinho. Carvalho, F. M., Bonfim, T. A. S., Cirino, C. A. S., \& Ferreira, I. S. (2006). Condiçōes de trabalho e saúde mental dos médicos de Salvador, Bahia, Brasil. Cadernos de Saúde Pública, 22 (1), 131 140 .

Nogueira-Martins, L. A. (2003). Saúde mental dos profissionais de saúde. Revista Brasileira de Medicina do Trabalho, 1 (1), 59-71.

Paula, A. P. P. (2005). Administração pública brasileira entre o gerencialismo e a gestão social. RAE. Revista de Administração de Empresas, 45 (1), 36-49.

Paula, A. P. P. (2010). Por uma nova gestão pública: reinserindo o debate a partir das práticas possíveis. In A. S. Cunha, B. A. Medeiros, \& , L. C. Aquino (Org.) Estado, instituiçôes e democracia: República. (pp. 505-530). Brasília: IPEA.

Peduzzi, M. (2002). Mudanças tecnológicas e seu impacto no processo de trabalho em saúde. Trabalho, Educação e Saúde, 1 (1), 75-91.

Ribeiro, C.V.S. (2009).Asaúdedoservidor públicoem temposdegerencialismo. Anais do Encontro Nacional da Abrapso, 15. Maceió: UFAL. Recuperado em 15 fevereiro, 2012, de http://www.abrapso.org.br/siteprincipal/images/ Anais_XVENABRAPSO/169.\%20a\%20sa\%DAde\%20do\%20servidor\%20 p\%DAblico\%20em\%20tempos\%20de\%20gerencialismo.pdf

Ronzani, T. M., Stralen, C. J. (2003). Dificuldades de implantação do Programa de Saúde da Família como estratégia de reforma do sistema de saúde brasileiro. Revista APS, 6 (2), 99-107.

Santos, J. B. F., Andrade, J. T., Meneleu Neto, J., Rodrigues, R. L., Pinheiro, C. H. L., \& Oliveira, F. E. (2006). O trabalho do médico: de profissional liberal a assalariado. In: Santos, J. B. F. (Org.). Observatório de Recursos Humanos em Saúde - estação Cetrede/UFC/UECE: reflexões de pesquisas. (pp. 42-72). Fortaleza: Eduece.

Santos, N. R. (2008). Política pública de saúde no Brasil: encruzilhada, buscas e escolhas de rumos. Ciência \& Saúde Coletiva, 13 (suppl. 2), 2009-2018.

Schraiber, L. B. (1995). O trabalho médico: questôes acerca da autonomia profissional. Cadernos de Saúde Pública, 11 (1), 57-64.

Schraiber, L. B. (2000). A profissão de ser médico. In A. M. Canesqui (Org.). Ciências sociais e saúde para o ensino médico. (pp. 75-98). São Paulo: Hucitec. 
Schraiber, L. B. (2008). O médico e suas interaçôes: a crise dos vínculos de confiança. São Paulo: Aderaldo \& Rothschild.

Sousa, M. F., \& Hamann, E. M. (2009). Programa Saúde da Família no Brasil: uma agenda incompleta? Ciência \& Saúde Coletiva, 14 (suppl. 1), $1325-1335$.

Wood, T. Junior \& Paula, A. P. P. (2010). O culto da performance e o indivíduo S.A. In: Ehrenberg, A. O culto da performance. (pp. 197-208). Aparecida: Ideias \& Letras.

Yin, R. K. (2005). Estudo de caso: planejamento e métodos.(3a ed.). Porto Alegre: Bookman. 